\title{
Toll-Like Receptor Responses in IRAK-4-Deficient Neutrophils
}

\author{
Robin van Bruggen ${ }^{a} \quad$ Agata Drewniak $^{a, b} \quad$ Anton T.J. Tool $^{a}$ Machiel Jansen $^{a}$ \\ Michel van Houdt ${ }^{a}$ Judy Geissler ${ }^{\mathrm{a}} \quad$ Timo K. van den Berg $^{\mathrm{a}}$ Helen Chapel ${ }^{\mathrm{c}}$ \\ Taco W. Kuijpers ${ }^{a, b}$ \\ a Sanquin Research and Landsteiner Laboratory, and ' ${ }^{\mathrm{b}}$ Emma Children's Hospital, Academic Medical Center, \\ University of Amsterdam, Amsterdam, The Netherlands; ' ${ }^{\mathrm{D}}$ Department of Clinical Immunology, \\ Nuffield Department of Medicine, John Radcliffe Hospital, Oxford, UK
}

\section{Key Words}

Neutrophil $\cdot$ IRAK-4 · Toll-like receptors

\begin{abstract}
Human neutrophils were found to express all known Toll-like receptors (TLRs) except TLR3 and TLR7. IRAK-4-deficient neutrophils were tested for their responsiveness to various TLR ligands. Essentially all TLR responses in neutrophils, including the induction of reactive oxygen species generation, adhesion, chemotaxis and IL- 8 secretion, were found to be dependent on IRAK-4. Surprisingly, the reactivity towards certain established TLR ligands, imiquimod and ODN-CpG, was unaffected by IRAK-4 deficiency, demonstrating their activity is independent of TLR. TLR-4-dependent signaling in neutrophils was totally dependent on IRAK-4 without any major TRIF-mediated contribution. We did not observe any defects in killing capacity of IRAK-4-deficient neutrophils for Staphylococcus aureus, Escherichia coli and Candida albicans, suggesting that microbial killing is primarily TLR independent.

Copyright $\odot 2009$ S. Karger AG, Basel
\end{abstract}

R. van Bruggen and A. Drewniak contributed equally to this work.

\section{Introduction}

Neutrophils play a central role in the immune response against bacterial and fungal infections [1]. After migration into the site of infection, neutrophils phagocytose the invading pathogens. They subject them to a large array of microbicidal compounds, such as high concentrations of reactive oxygen species (generated by the NADPH oxidase) and proteolytic enzymes, which leads to the degradation of the ingested microbe $[1,2]$. Neutrophils are equipped with pattern-recognition receptors such as Dectin-1 [3] and Toll-like receptors (TLRs) [4] for the recognition of pathogen-associated molecular patterns, such as $\beta$-glucans and lipopolysaccharide (LPS), which are displayed by microbes. Most neutrophil functions, including reactive oxygen species production, IL-8 secretion, motility and apoptosis, can be regulated by TLR signaling [5]. Upon ligation of TLRs, an adapter molecule known as MyD88 is recruited through interaction of its Toll-IL-1 receptor (TIR) domain with the TIR domain located in the cytoplasmic tail of TLRs [6]. Then, IL-1 receptor-associated kinase (IRAK)-1 and IRAK-4 are recruited to the signaling complex by interaction with MyD88 [7]. This leads to hyperphosphorylation of IRAK-

\section{KARGER \\ Fax +4161306 1234 \\ E-Mail karger@karger.ch}

www.karger.com
(C) 2009 S. Karger AG, Basel

$1662-811 \mathrm{X} / 10 / 0023-0280 \$ 26.00 / 0$

Accessible online at:

www.karger.com/jin
Dr. Robin van Bruggen

Sanquin Research and Landsteiner Laboratory, Academic Medical Center University of Amsterdam, Plesmanlaan 125

NL-1066 CX Amsterdam (The Netherlands)

Tel. +31 20512 3259, Fax +31 20512 3310, E-Mail r.vanbruggen@ sanquin.nl 
1 by IRAK- 4 and subsequent recruitment of TNFR-associated factor 6 (TRAF6) [8]. The TRAF6/IRAK-1 complex then dissociates from the receptor and induces further signaling, which ultimately leads to NF- $\mathrm{B}$ and MAPK activity [9]. All TLRs are believed to generate MyD88-dependent signals, but TLR3 and TLR4 can also provide MyD88-independent signaling via TRIF and Tram $[10,11]$. IRAK-4 deficiency in humans has been described to result in several defects in the immune responses to pathogens, such as a lack of induction of IFN$\alpha$ and $-\beta$ production in response to viral stimulation of TLR7, 8 and 9 [12] and a defect in generating a sustained antibody response during childhood [13]. Moreover, IRAK-4, as well as MyD88, have been shown to be pivotal in the negative selection of autoreactive B cells, although this defect does not seem to lead to high titers of autoreactive antibodies in these patients, nor do these patients develop autoimmune diseases [14].

In clinical terms, neutrophil defects are suspected in patients suffering from recurrent invasive infections caused by Staphylococcus aureus or Gram-negative strains such as Pseudomonas aeruginosa and (non-typhoid) Salmonella species - among many other but less common and often opportunistic microbes. Chronic granulomatous disease is the most frequently diagnosed phagocyte defect that is associated with infections by these pathogens [15]. Also, in patients with IRAK-4 deficiency a similar range of pathogens are met [16], and the occurrence of Shigella sonnei meningitis in a patient that had suffered previously from $S$. aureus and $P$. aeruginosa infections suggested that IRAK-4 may play an important role in human neutrophil function [17]. Human neutrophils have been reported to express all TLRs apart from TLR3 [5], and all TLRs have been described to be defective in functional screening tests by shedding of the surface-expressed protein CD62L in a series of IRAK-4-deficient patients [18]. We therefore decided to test the neutrophil functions in IRAK-4 deficiency in greater detail.

\section{Materials and Methods}

\section{Patient History}

The patient is the eldest of 3 siblings born to non-consanguineous white parents of English descent in 1974. As previously described [19], she had a history of skin abscesses caused by $S$. aureus, Streptococcus pyogenes and $P$. aeruginosa during early childhood. Subsequently, she suffered from an invasive purulent arthritis caused by Streptococcus pneumoniae and S. sonnei septicemia/meningitis at 7 and 10 years of age, respectively. Under all conditions she was treated with antibiotics and recovered completely. These infectious episodes were not accompanied by acute-phase responses. Following the clinically noticeable Shigella infection, the patient has had consecutive episodes of invasive staphylococcal disease, without systemic illness. Since the age of 26 she had not suffered from major infections. At the time of writing the patient was almost 36 years old and had been doing well since prophylactic antibiotic treatment was stopped several years ago.

\section{Neutrophil NADPH Oxidase Activity, Migration and} Adhesion

Heparinized venous blood was collected from healthy donors and from the patient, after obtaining informed consent. Blood studies were approved by the local institutional medical ethical committees in accordance with the standards laid down in the 1964 declaration of Helsinki.

Granulocytes were isolated as described [20, 21]. Hydrogen peroxide production, chemotaxis and adhesion were assessed as previously described [22]. TLR agonists were used at the following concentrations, unless otherwise noted: LPS/LPS-binding protein (LBP; $20 \mathrm{ng} / \mathrm{ml}$, LPS isolated from Escherichia coli strain 055:B5; Sigma Aldrich, St. Louis, Mo., USA; LBP 50 ng/ml; R\&D Systems), Pam3Cys-SK4 (20 $\mu \mathrm{g} / \mathrm{ml}$; EMC Microcollections, Tübingen, Germany); MALP-2 (1 $\mu \mathrm{g} / \mathrm{ml}$, EMC Microcollections); imiquimod (50 $\mu \mathrm{g} / \mathrm{ml}$; InvivoGen, San Diego, Calif., USA); resiquimod $(50 \mu \mathrm{g} / \mathrm{ml}$, Alexis Biochemicals, Lausanne, Switzerland), CpG-ODN (M362, $50 \mu \mathrm{g} / \mathrm{ml}$, InvivoGen). We used as nonTLR ligands TNF- $\alpha$ (10 ng/ml, Peprotech EC, London, UK), platelet-activating factor (PAF; $1 \mu \mathrm{M}$, Sigma), fMLP (1 $\mu \mathrm{M}$, Sigma), PMA (100 ng/ml, Sigma) and zymosan ( $1 \mathrm{mg} / \mathrm{ml}$; MP Biomedicals, Solon, Ohio, USA) were used. Results represent at least 3 independent experiments, in which 1- or 2-day controls were included.

\section{Killing of Microorganisms by Human Neutrophils}

Bactericidal activity of granulocytes was determined as previously described [23]. In brief, E. coli (strain ML-35) and S. aureus (strain 502A) were grown aerobically at $37^{\circ} \mathrm{C}$ overnight in $\mathrm{LB}$ broth. The next day, $1 \mathrm{ml}$ of this culture was added to $30 \mathrm{ml}$ of $\mathrm{LB}$, and grown for another 2 to $3 \mathrm{~h}$. Subsequently, the bacteria were collected by centrifugation, washed twice in PBS and re-suspended in HEPES medium to an $\mathrm{OD}_{600}$ of 1 (i.e. $10^{9}$ bacteria $/ \mathrm{ml}$ ). After opsonization $\left[10 \%(\mathrm{v} / \mathrm{v})\right.$ pooled serum, $15 \mathrm{~min}$, at $\left.37^{\circ} \mathrm{C}\right]$, bacteria were added at a ratio of $5: 1$ neutrophil $\left(4 \times 10^{6} \mathrm{cells} / \mathrm{ml}\right)$. At the desired time points, $50-\mu \mathrm{l}$ samples were diluted in $2.5 \mathrm{ml}$ of water/ $\mathrm{NaOH}$ at $\mathrm{pH}$ 11.0. At the end of the incubation period, the viable bacteria in each sample were determined by the pour-plate method in LB agar. The CFU were counted after an overnight incubation at $37^{\circ} \mathrm{C}$, and the percentage killing was calculated.

Killing of Candida albicans was determined by use of FACS analysis of GFP-expressing cells. It has been shown before that there is a strong correlation between the GFP positivity and the ability of fungal conidia to germinate [24]. C. albicans stably transfected with GFP was a generous gift of Dr. Alexander Johnson (Department of Microbiology and Immunology, University of California, San Francisco, Calif., USA). Yeast was cultured in $\mathrm{LB}$ medium overnight at $30^{\circ} \mathrm{C}$. Cells were collected by centrifugation at 2,000 $\mathrm{g}$ for $5 \mathrm{~min}$, washed twice in PBS, and suspended to the required absorbance at $630 \mathrm{~nm}$. For the actual killing experiments, the yeast to neutrophil ratio was $4: 1$. Samples were analyzed by FACS; GFP-positive cells were considered to be alive. 
IL-8 Release of Neutrophils

Neutrophils were stimulated overnight with the indicated TLR ligands. IL- 8 was measured in the supernatants using a Pelikine IL-8 ELISA (Sanquin Reagents, Amsterdam, The Netherlands).

\section{Results and Discussion}

Because of an apparent defect in anti-bacterial immunity in an IRAK-4-deficient patient, the neutrophils from this patient were subjected to a series of functional tests in which the effect of established TLR-specific ligands as well as that of typical TLR-independent stimuli was evaluated. First, we performed respiratory burst assays on isolated neutrophils. IRAK-4-deficient neutrophils showed normal hydrogen peroxide secretion after stimulation with PMA, fMLP stimulation after PAF priming, or serum-treated zymosan (fig. 1a). Unexpectedly, we observed a normal respiratory burst provoked by unopsonized zymosan as well, which we anticipated to be impaired since this response is assumed to be TLR2 dependent [3]. Moreover, when performed in the presence of CD11b-blocking antibodies to inhibit the CD11b/CD18 (CR3)-dependent phagocytosis [22], we found that zymosan-priming of the fMLP-induced burst was also normal (fig. 1b), even though secretion of hydrogen peroxide is low compared to other stimuli. Clearly, zymosan signals in a TLR2/IRAK4independent manner into the neutrophil.
Other well-defined TLR2-priming agents, PAM3CysSK4 (TLR1/TLR2) and MALP2 (TLR2/TLR6), were completely ineffective in priming reactive oxygen species production in response to fMLP in IRAK-4-deficient neutrophils (fig. 1b).

This proved to be true as well for other TLR ligands such as LPS (TLR4) and resiquimod (TLR7 and 8). PolyIC (TLR3) was unable to activate human neutrophils, which is in line with our finding that mRNA transcripts for TLR3 were not detected in these cells (online supplementary table 1; all online material is available at www. karger.com/doi/10.1159/000268288).

Several notable findings were made. First, we found priming of hydrogen peroxide secretion in response to ODN-CpG (TLR9) to be unaffected in IRAK-4-deficient neutrophils. Recently, it has been postulated that TLR9 can still signal in the absence of IRAK-4 in neutrophils through the activation of PI3K in an IRAK-4-independent manner in human neutrophils, although the possibility that ODN-CpG signals via an alternative receptor on neutrophils was not investigated in that report [25]. In fact, the kinetics of the fMLP-induced hydrogen peroxide production in response to ODN-CpG were found to be completely different from that provoked by the other TLR ligands, which is also consistent with an alternative activation pathway (online suppl. fig. 1). Furthermore, in a report by Doyle et al. [26], ODN-CpG signaling was found to depend on $b t k$, a non-receptor tyrosine kinase expressed in B cells and myeloid cells and mutated in X-
Fig. 1. Various responses in IRAK-4-deficient neutrophils. a Hydrogen peroxide production $(\mathrm{nmol} / \mathrm{min})$ by neutrophils $\left(2.5 \times 10^{5} / \mathrm{ml}\right)$ in response to the indicated stimuli. Maximal activities (mean $\pm \mathrm{SD}$ of 3 experiments) were measured during $30 \mathrm{~min}$ of incubation. PMNs = Polymorphonuclear leukocytes; STZ = serumtreated zymosan.

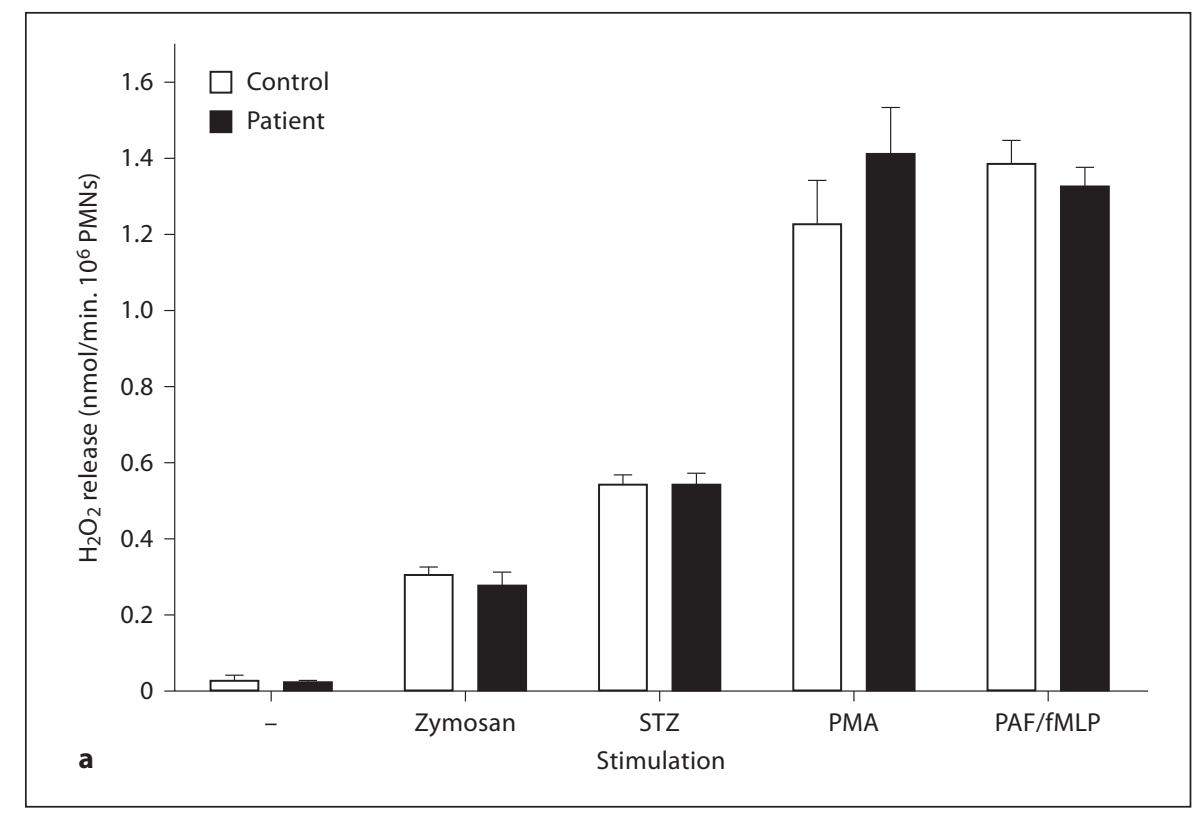


Fig. 1. Various responses in IRAK-4-deficient neutrophils. b Priming of the fMLPinduced respiratory burst by the indicated stimuli. Neutrophils were first primed with the indicated stimuli, and then stimulated with fMLP. c Adhesion in response to the indicated TLR and non-TLR agonists. $\mathrm{PMNs}=$ Polymorphonuclear leukocytes.
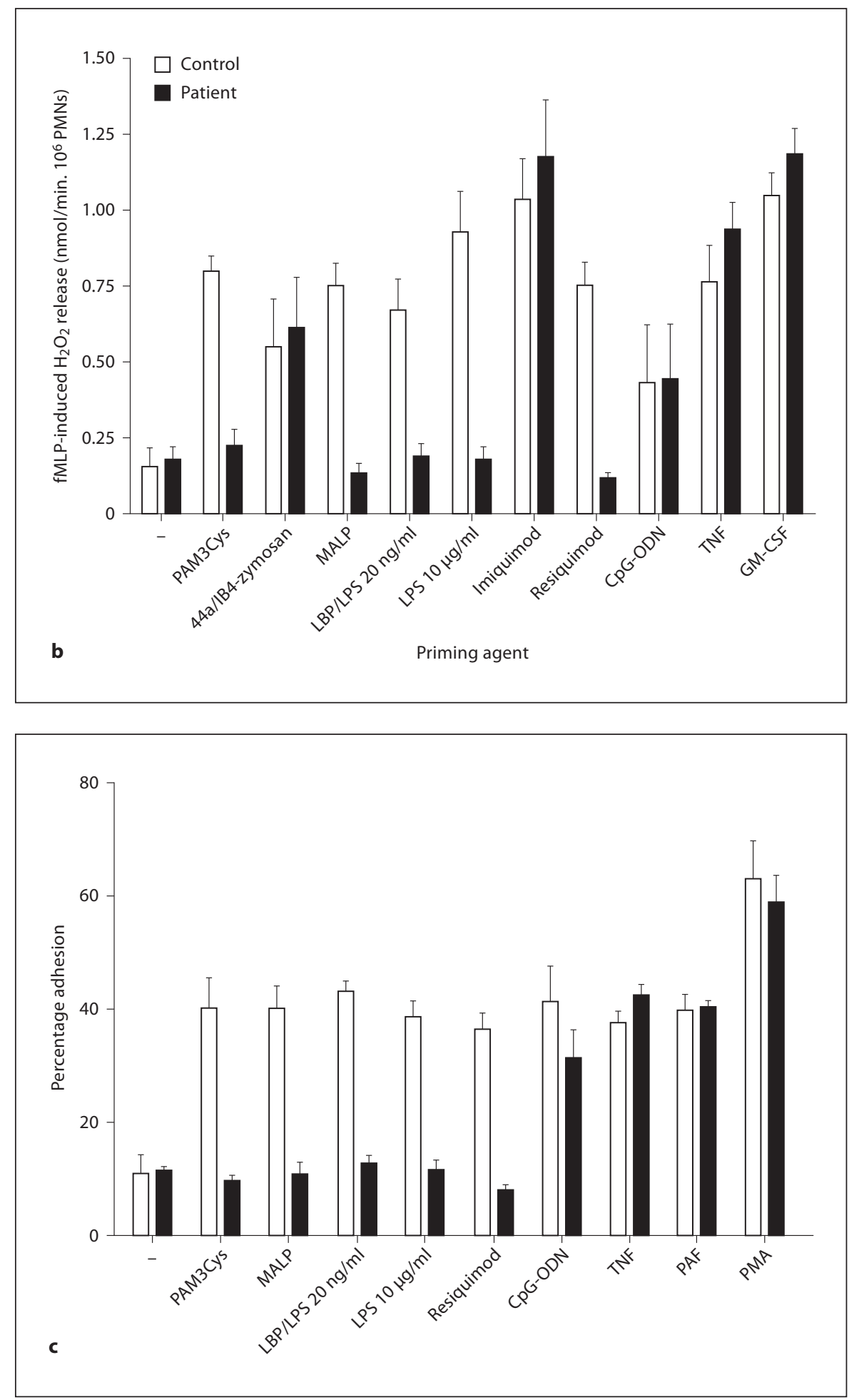


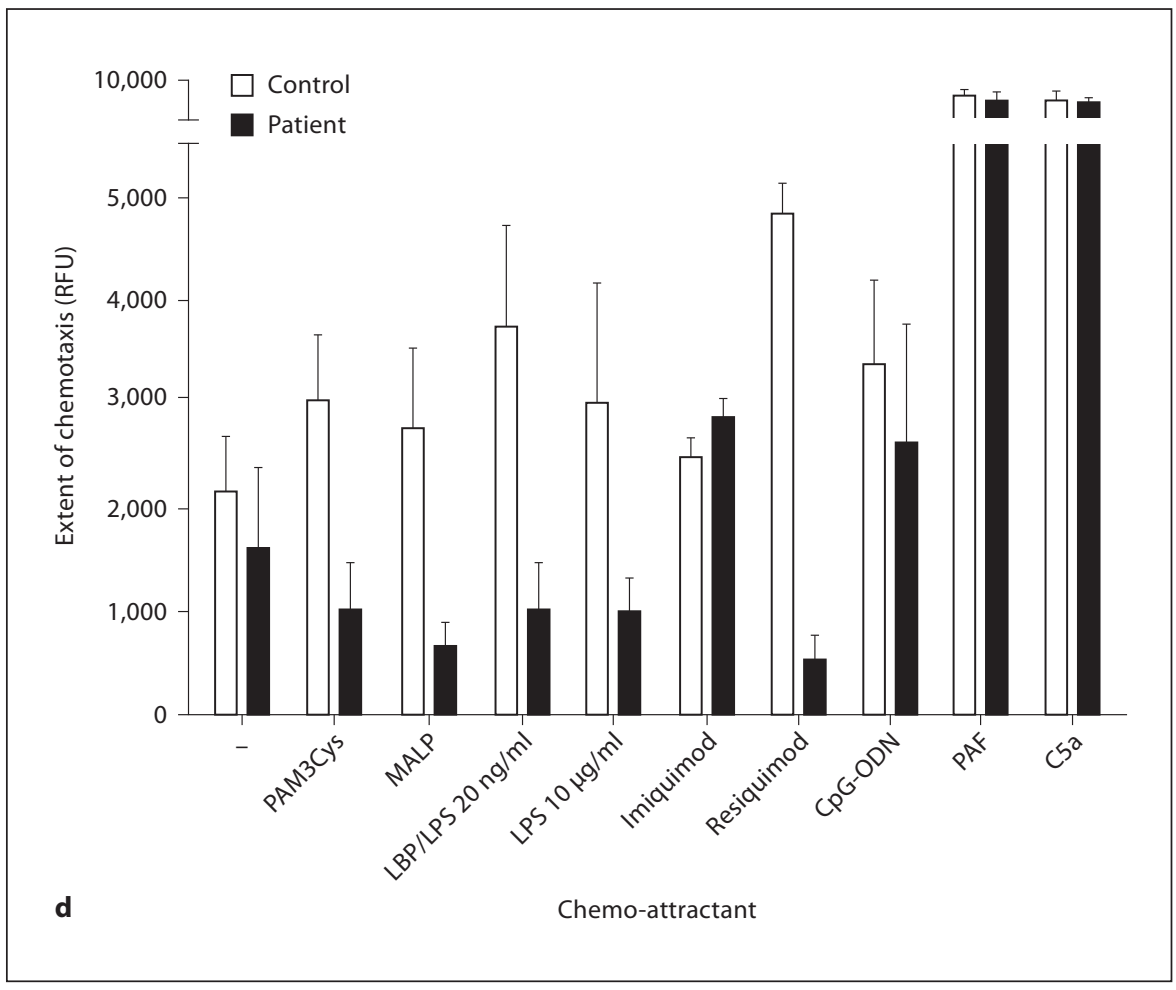

Fig. 1. Various responses in IRAK-4-deficient neutrophils. d Chemokinesis induced by various TLR ligands. e IL- 8 release of IRAK-4-deficient neutrophils.

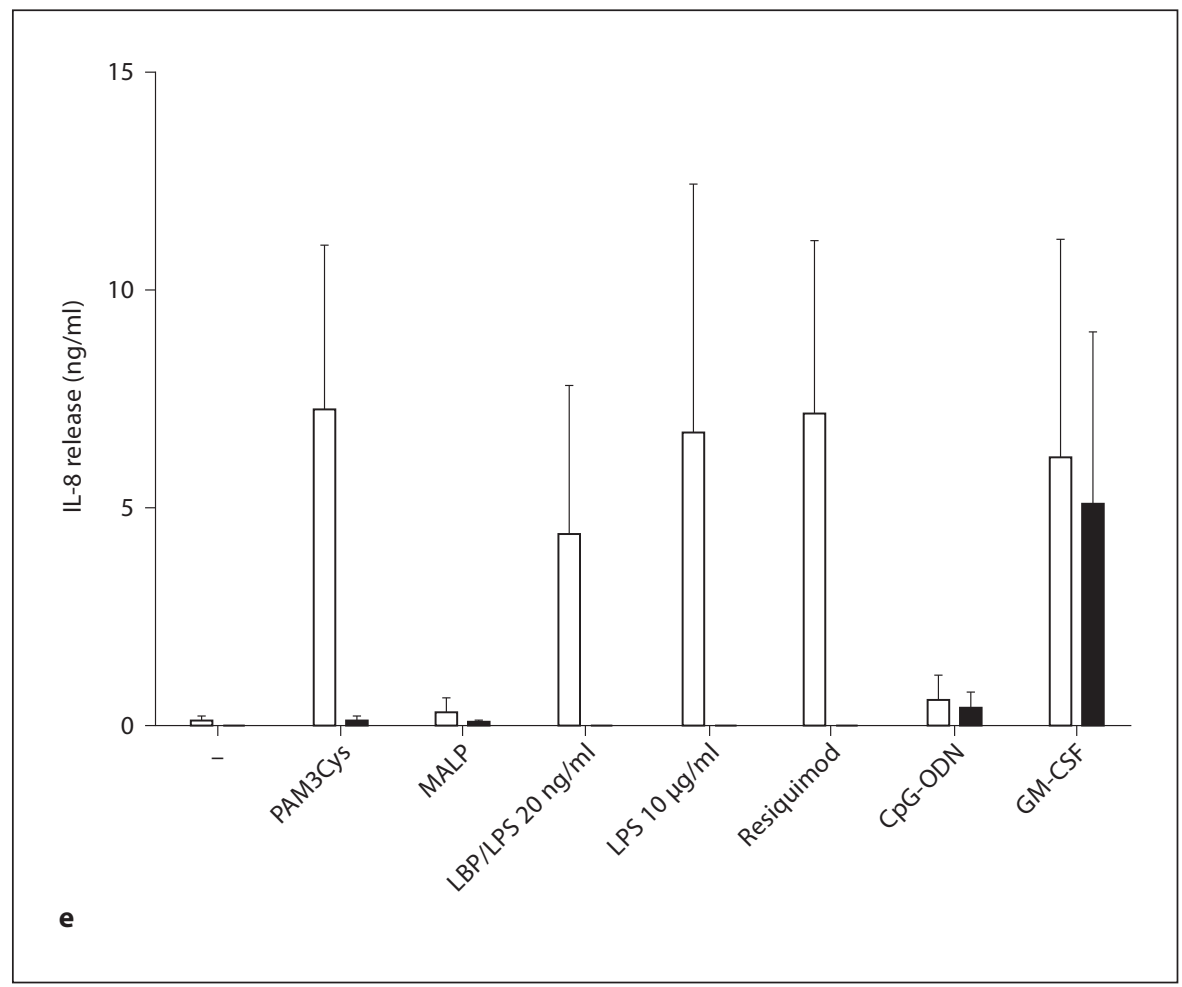


linked agammaglobulinemia. Therefore, we have tested neutrophils of genetically defined X-linked agammaglobulinemia patients but found no difference in CpGmediated neutrophil activation (data not shown).

Secondly, in the assays described above imiquimod (a presumed TLR7 ligand) was also tested and found to evoke normal responses in IRAK-4-deficient neutrophils. Taking into account that resiquimod (TLR7 or TLR8) induces responses that are completely IRAK-4 dependent, the observed effects of imiquimod on IRAK-4deficient neutrophils are likely to be mediated through an alternative receptor. Indeed, imiquimod has been shown to be able to affect signaling through adenosine receptors [27]. Furthermore, neutrophils express several members of this family of receptors and their signaling could be expected to influence at least some of the responses tested in this study [28], making it likely that the effects induced by imiquimod in IRAK-4-deficient neutrophils may be dependent on adenosine receptors instead of TLR7. In line with this, transcripts for TLR7 were undetectable in neutrophils. In contrast, we observed high levels of mRNA of TLR8, which appears therefore primarily responsible for the IRAK-4-dependent effects of resiquimod in neutrophils (fig. 1, online suppl. table 1).

Finally, TLR4 in neutrophils seems to be unable to signal via the established alternative, TRIF-dependent, MyD88-independent route [29].

In fact, transcripts and proteins for IFN- $\alpha / \beta$ or CCL 4 as commonly tested TRIF-dependent activation products remained unaffected by LPS in neutrophils, but were upregulated in monocytes. Moreover, TRIF was undetectable at the protein level by Western blotting, again with monocytes as a positive control (data not shown).

Other neutrophil responses induced by TLR stimulation were also tested. First, adhesion in response to TLR ligands was monitored. The same picture emerged as in the NADPH-oxidase priming experiments, responses to LPS either in high concentration or in the presence of LBP, PAM3Cys-SK4, MALP2 and resiquimod were blocked in the IRAK-4-deficient neutrophils, whereas ODN-CpG induced adhesion to the same extent as in control neutrophils (fig. 1c). Also chemokinesis after TLR stimulation proved to be absent in IRAK-4-deficient neutrophils (fig. 1d). Finally, IL-8 secretion by IRAK-4-deficient neutrophils proved to be severely decreased for the various TLR ligands tested (fig. 1e), which is also in line with previously published data [25]. A very low IL-8 response to ODN-CpG was detected in both the control neutrophils and in the IRAK-4 neutrophils tested in this study.

TLR Responses in IRAK-4-Deficient Neutrophils
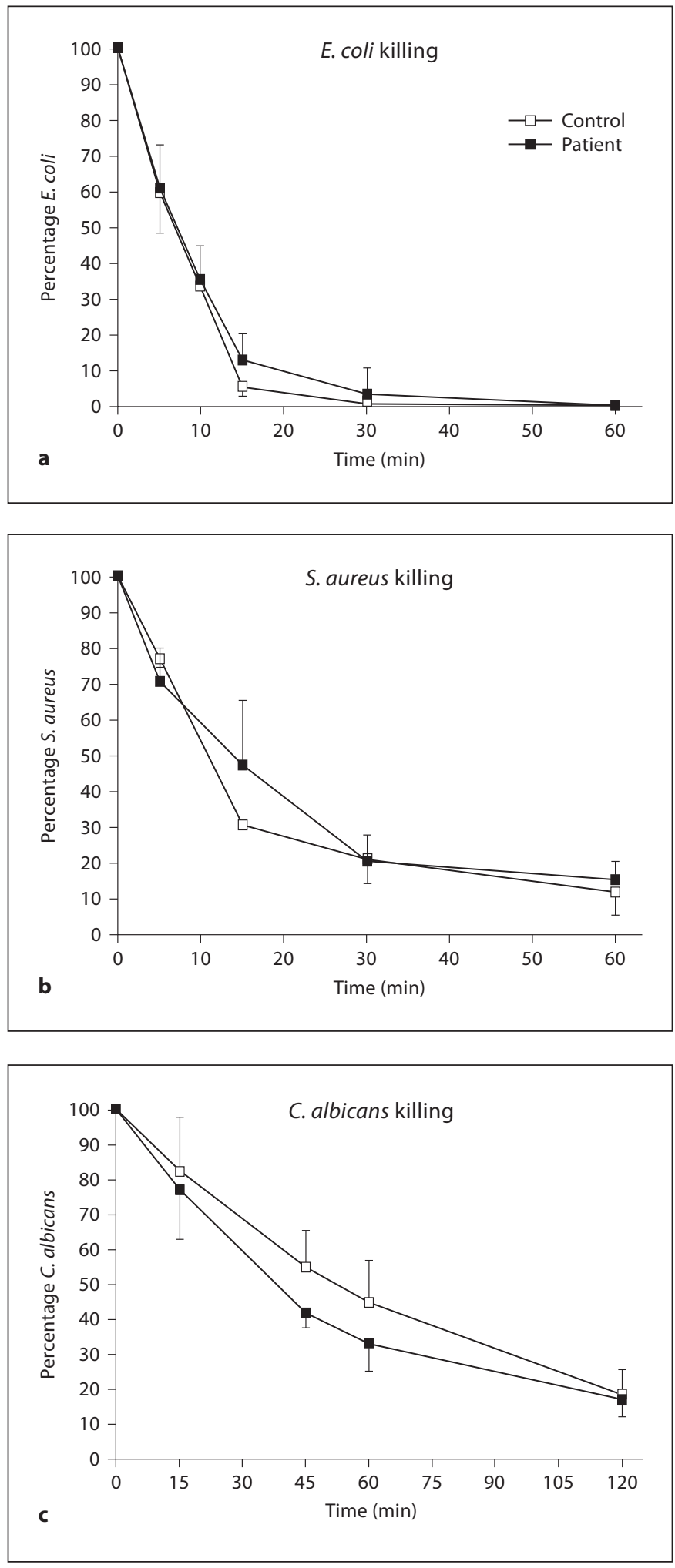

Fig. 2. Killing of various microbes by IRAK-4-deficient neutrophils. Killing of a opsonized E. coli, b opsonized S. aureus and c unopsonized C. albicans by IRAK-4-deficient neutrophils (mean $\pm \mathrm{SD}$ of 3 experiments).

J Innate Immun 2010;2:280-287 
We also tested killing of $S$. aureus, E. coli and C. albicans, the latter were tested in unopsonized form (fig. 2a, $b, c)$. No differences in killing were detected between control and IRAK-4-deficient neutrophils.

Collectively, these data show the complete unresponsiveness of IRAK-4-deficient neutrophils to stimulation with TLR ligands, such as PAM3Cys-SK4 (TLR1/2), MALP-2 (TLR2/6), LPS (TLR4) and resiquimod (TLR7/8). This strongly supports our conclusion that TLR responses in general, at least in neutrophils, are completely IRAK4 dependent. We believe that it is reasonable to assume, for reasons outlined above, that the response to other presumed TLR ligands in neutrophils, i.e. imiquimod and ODN-CpG, involves TLR-independent pathways. Furthermore, the observation that killing of different pathogens by IRAK-4-deficient neutrophils was not altered, essentially demonstrates that the intracellular killing of bacteria and fungi by neutrophils is independent of recognition by TLRs. Since the clinical manifestations of IRAK-4 deficiency become less severe with age, these findings support the idea that a strict TLR dependence of pathogen recognition by innate immune cells occurs primarily in young individuals. This can probably be compensated for by other recognition systems, such as antibodies, that can be acquired during aging.

\section{Acknowledgments}

R. van Bruggen is supported by a grant from the Landsteiner Stichting voor Bloedtransfusie Research (LSBR). H. Chapel is supported by NIHR Oxford Biomedical Centre, EU 7th Framework Programme (PADnet), the Primary Immunodeficiency Association, Baxter Healthcare and the Jeffrey Modell Foundation.

\section{References}

1 Nauseef WM: How human neutrophils kill and degrade microbes: an integrated view. Immunol Rev 2007;219:88-102.

2 Pham CT: Neutrophil serine proteases: specific regulators of inflammation. Nat Rev Immunol 2006;6:541-550.

-3 Brown GD: Dectin-1: a signalling non-TLR pattern-recognition receptor. Nat Rev Immunol 2006;6:33-43.

4 Iwasaki A, Medzhitov R: Toll-like receptor control of the adaptive immune responses. Nat Immunol 2004;5:987-995.

5 Hayashi F, Means TK, Luster AD: Toll-like receptors stimulate human neutrophil function. Blood 2003;102:2660-2669.

6 Wesche H, Henzel WJ, Shillinglaw W, Li S, Cao Z: MyD88: an adapter that recruits IRAK to the IL-1 receptor complex. Immunity 1997;7:837-847.

7 Cao Z, Henzel WJ, Gao X: IRAK: a kinase associated with the interleukin-1 receptor. Science 1996;271:1128-1131.

8 Cao Z, Xiong J, Takeuchi M, Kurama T, Goeddel DV: TRAF6 is a signal transducer for interleukin-1. Nature 1996;383:443446.

9 O'Neill LA, Bowie AG: The family of five: TIR-domain-containing adaptors in Tolllike receptor signalling. Nat Rev Immunol 2007;7:353-364.

10 Yamamoto M, Sato S, Hemmi H, Uematsu S, Hoshino K, Kaisho T, Takeuchi O, Takeda K, Akira S: TRAM is specifically involved in the Toll-like receptor 4-mediated MyD88-independent signaling pathway. Nat Immunol 2003;41:144-150.
Fitzgerald KA, Rowe DC, Barnes BJ, Caffrey DR, Visintin A, Latz E, Monks B, Pitha PM, Golenbock DT: LPS-TLR4 signaling to IRF3/7 and NF-kappaB involves the Toll adapters TRAM and TRIF. J Exp Med 2003;198: 1043-1055.

12 Yang K, Puel A, Zhang S, Eidenschenk C, Ku CL, Casrouge A, Picard C, von Bernuth H, Senechal B, Plancoulaine S, Al-Hajjar S, AlGhonaium A, Maródi L, Davidson D, Speert D, Roifman C, Garty BZ, Ozinsky A, Barrat FJ, Coffman RL, Miller RL, Li X, Lebon P, Rodriguez-Gallego C, Chapel H, Geissmann F, Jouanguy E, Casanova JL: Human TLR-7-, $-8-$, and -9-mediated induction of IFN-alpha/beta and -lambda is IRAK-4 dependent and redundant for protective immunity to viruses. Immunity 2005;23:465-478.

13 Day N, Tangsinmankong N, Ochs H, Rucker R, Picard C, Casanova JL, Haraguchi S, Good R: Interleukin receptor-associated kinase (IRAK-4) deficiency associated with bacterial infections and failure to sustain antibody responses. J Pediatr 2004;144:524526.

14 Isnardi I, Ng YS, Srdanovic I, Motaghedi R, Rudchenko S, von Bernuth H, Zhang SY, Puel A, Jouanguy E, Picard C, Garty BZ, Camcioglu Y, Doffinger R, Kumararatne D, Davies G, Gallin JI, Haraguchi S, Day NK, Casanova JL, Meffre E:IRAK-4- and MyD88dependent pathways are essential for the removal of developing autoreactive $B$ cells in humans. Immunity 2008;29:746-757.

15 Heyworth PG, Cross AR, Curnutte JT: Chronic granulomatous disease. Curr Opin Immunol 2003;15:578-584.
16 Picard C, Puel A, Bonnet M, Ku CL, Bustamante J, Yang K, Soudais C, Dupuis S, Feinberg J, Fieschi C, Elbim C, Hitchcock R, Lammas D, Davies G, Al-Ghonaium A, AlRayes H, Al-Jumaah S, Al-Hajjar S, AlMohsen IZ, Frayha HH, Rucker R, Hawn TR, Aderem A, Tufenkeji H, Haraguchi S, Day NK, Good RA, Gougerot-Pocidalo MA, Ozinsky A, Casanova JL: Pyogenic bacterial infections in humans with IRAK-4 deficiency. Science 2003;299:2076-2079.

17 Chapel H, Puel A, von Bernuth H, Picard C, Casanova JL: Shigella sonnei meningitis due to interleukin-1 receptor-associated kinase4 deficiency: first association with a primary immune deficiency. Clin Infect Dis 2005;40: 1227-1231.

$18 \mathrm{Ku}$ CL, von Bernuth H, Picard C, Zhang SY, Chang HH, Yang K, Chrabieh M, Issekutz AC, Cunningham CK, Gallin J, Holland SM, Roifman C, Ehl S, Smart J, Tang M, Barrat FJ, Levy O, McDonald D, Day-Good NK, Miller R, Takada H, Hara T, Al-Hajjar S, Al-Ghonaium A, Speert D, Sanlaville D, Li X, Geissmann F, Vivier E, Maródi L, Garty BZ, Chapel H, Rodriguez-Gallego C, Bossuyt X, Abel L, Puel A, Casanova JL: Selective predisposition to bacterial infections in IRAK-4-deficient children: IRAK-4-dependent TLRs are otherwise redundant in protective immunity. J Exp Med 2007;204:2407-2422.

19 Chapel H, Puel A, von Bernuth H, Picard C, Casanova JL: Shigella sonnei meningitis due to interleukin-1 receptor-associated kinase4 deficiency: first association with a primary immune deficiency. Clin Infect Dis 2005;40: 1227-1231. 
20 Roos D and de Boer M: Purification and cryopreservation of phagocytes from human blood. Methods Enzymol 1986;132:225243.

-21 Kuijpers TW, Tool ATJ, van der Schoot CE, Roos D, Verhoeven AJ: Upregulation of membrane surface antigens in neutrophils: a reappraisal on localization and function. Blood 1991;78:1105-1111.

22 Kuijpers TW, van Bruggen R, Kamerbeek N, Tool AT, Hicsonmez G, Gurgey A, Karow A, Verhoeven AJ, Seeger K, Sanal O, Niemeyer C, Roos D: Natural history and early diagnosis of LAD-1/variant syndrome. Blood 2007; 109:3529-3537.

23 Decleva E, Menegazzi R, Busetto S, Patriarca P, Dri P: Common methodology is inadequate for studies on the microbicidal activity of neutrophils. J Leukoc Biol 2006;79:8794.
24 Webb JS, Barratt SR, Sabev H, Nixon M, Eastwood IM, Greenhalgh M, Handley PS, Robson GD: Green fluorescent protein as a novel indicator of antimicrobial susceptibility in Aureobasidium pullulans. Appl Environ Microbiol 2001;67:5614-5620.

25 Hoarau C, Gérard B, Lescanne E, Henry D, François S, Lacapère JJ, El Benna J, Dang PM, Grandchamp B, Lebranchu Y, Gougerot-Pocidalo MA, Elbim C: TLR9 activation induces normal neutrophil responses in a child with IRAK-4 deficiency: involvement of the direct PI3K pathway. J Immunol 2007;179: 4754-4765.

26 Doyle SL, Jefferies CA, Feighery C, O’Neill LA: Signaling by Toll-like receptors 8 and 9 requires Bruton's tyrosine kinase. J Biol Chem 2007;282:36953-36960.
7 Schön MP, Schön M, Klotz KN: The small antitumoral immune response modifier imiquimod interacts with adenosine receptor signaling in a TLR7- and TLR8-independent fashion. J Invest Dermatol 2006;126:13381347.

28 Fortin A, Harbour D, Fernandes M, Borgeat P, Bourgoin S: Differential expression of adenosine receptors in human neutrophils: upregulation by specific Th1 cytokines and lipopolysaccharide. J Leukoc Biol 2006;79: 574-585.

29 Tamassia N, Le Moigne V, Calzetti F, Donini M, Gasperini S, Ear T, Cloutier A, Martinez FO, Fabbri M, Locati M, Mantovani A, McDonald PP, Cassatella MA: The MyD88independent pathway is not mobilized in human neutrophils stimulated via TLR4. J Immunol 2007;178:7344-7356. 